\title{
IN VITRO ИЗУЧЕНИЕ ЦИТОПРОТЕКТОРНОГО ДЕЙСТВИЯ 11-КИСЛОТНЫХ ПЕПТИДОВ, ПОЛУЧЕННЫХ ПУТЕМ МОДИФИКАЦИИ ПЕПТИДА НВSP (ARA290)
}

\author{
М.В. Корокин, О.В. Анциферов, В.О. Солдатов, А.А. Победа, \\ Л.В. Корокина, Э.И. Таран
}

Белгородский государственный национальный исследовательский университет, ул. Победы, д. 85, г. Белгород, 308015, Российская Федерация

DOI: 10.19163/MedChemRussia2021-2021-110

E-mail: mkorokin@mail.ru

Ранее мы провели исследование эндотелиопротивнойактивности пептида рHBSP c аминокислотной последовательностью QEQLERALNSS и пришли к выводу, что поиск пептидов, обладающих цитопротективным и эндотелиопротективным действием следует осуществлять среди родственных исходному пептиду рHBSP, но не обладающих протромботической активностью или обладающих антикоагулянтными свойствами.

В настоящем исследовании на культуре клеток HUVEC (Sigma-Aldrich (Merck)) мы проанализировали цитопротекторное действие следующих производных 11-членного пептида pHBSP (QEQLERALNSS): EP-11-1 (UEHLERALNSS), EP-11-2 (UEQLERALNCS), EP-11-3 (UEQLERALNTS). HUVEC культивировали в среде DMEM по стандартной методике. Клетки помещали в 96-луночные планшеты, покрытые желатином, с плотностью 5 тысяч клеток на лунку. Через 24 ч инкубации исследуемые пептиды (рHBSP, EP-11-01, EP-11-02, EP-11-03) вводили в 3-х концентрациях - 5 мкг/мл, 30 мкг / мл и 50 мкг/мл. Выживаемость эндотелиоцитов оценена с помощью МТТ-теста, характеризующем митохондриальную активность клеток.

При исследовании установлено, что исследуемые соединения обладают выраженным цитопротекторным действием, статистически значимо повышая митохондриальную активность и выживаемость клеток в культуре (табл. 1).

Таблица 1.

Оптическая плотность раствора формазана в ДМСО в опытных группах (единицы оптической плотности, ед., $\mathrm{M} \pm \mathbf{m}, \mathbf{n = 8}$ )

\begin{tabular}{|l|l|l|l|}
\hline \multirow{2}{*}{ Экспериментальные группы } & \multicolumn{3}{|c|}{ Концентрация пептидов в культуре } \\
\cline { 2 - 4 } & \multicolumn{1}{|c|}{$\mathbf{5}$ мкг/мл } & \multicolumn{1}{|c|}{$\mathbf{3 0}$ мкг/мл } & \multicolumn{1}{c|}{$\mathbf{5 0}$ мкг/мл } \\
\hline $\mathrm{HUVEC}$ & $0,9251 \pm 0,061$ & $0,8935 \pm 0,056$ & $0,9063 \pm 0,072$ \\
\hline $\mathrm{HUVEC}+\mathrm{H}_{2} \mathrm{O}_{2}$ & $0,3422 \pm 0,069^{*}$ & $0,3205 \pm 0,044^{*}$ & $0,3927 \pm 0,051^{*}$ \\
\hline $\mathrm{HBSP}+\mathrm{HUVEC}+\mathrm{H}_{2} \mathrm{O}_{2}$ & $0,5617 \pm 0,042^{* *}$ & $0,5872 \pm 0,051^{* *}$ & $0,5491 \pm 0,031^{* *}$ \\
\hline EP-11-1+ HUVEC $+\mathrm{H}_{2} \mathrm{O}_{2}$ & $0,5472 \pm 0,39^{* *}$ & $0,6160 \pm 0,089^{* *}$ & $0,6452 \pm 0,025^{* *}$ \\
\hline EP-11-2+ HUVEC $+\mathrm{H}_{2} \mathrm{O}_{2}$ & $0,5944 \pm 0,041^{* *}$ & $0,5805 \pm 0,055^{* *}$ & $0,6112 \pm 0,062^{* *}$ \\
\hline EP-11-3+ HUVEC $+\mathrm{H}_{2} \mathrm{O}_{2}$ & $0,6943 \pm 0,035^{* * \#}$ & $0,7264 \pm 0,038^{* * \#}$ & $0,7436 \pm 0,040^{* * \#}$ \\
\hline
\end{tabular}

* $-p<0.05$ всравнениисHUVEC.

** - p<0.05 в сравнении сHUVEC + H2O2. \# - p<0.05 в сравнении pHBSP + HUVEC $+\mathrm{H}_{2} \mathrm{O}_{2}$

Работа выполнена при поддержке гранта Президента РФ № МД-757.2020.7.

$$
-110-
$$

